\title{
Externality Research of Electrical Ancillary Service
}

\section{Yonggang ZHU}

School of Electrical Engineering, Wuhan University, Wuhan, China

State Grid Hubei Electrical Power Company, Wuhan, China

Liming YING

School of Electrical Engineering, Wuhan University, Wuhan, China

$\mathrm{Hu}$ XIONG

State Grid Hubei Electric Power Research Institute, Wuhan, China

Fangmei BIE

School of Electrical Engineering, Wuhan University, Wuhan, China

ABSTRACT: Externalities constitute an important research area of modern western economics, and mark a distinctive feature of electric power auxiliary service (EPAS). By integrating the theory of externalities to the study of EPAS, this thesis ex-pounds the definition, category and influence of externalities of EPAS and proposes some solutions and suggestions to eradicate these externalities. At the preliminary stage of separating power plants from power grids, attention should be paid to the Pigovian Solution, which favors government intervention. However, Pigovian Solution has defects in itself, and with the development of power reform, Coase Solution based on market transactions is promoted, which creates an economic approach to deepen understanding of EPAS and build up the market of it.

KEYWORD: electric power market; auxiliary service; externalities

\section{PREFACE}

In addition to generating power for daily production, delivery and usage, electric power auxiliary service (EPAS) has provided a wide range of services to power-generating enterprises, power grid enterprises and users, such as frequency control, automatic generation control (AGC), peak shaving, reactive power regulation, backup and black start [1-4]. Auxiliary service is indispensable, which guarantees the safe and stable operation of electric power system and the quality of electricity as a commodity.

From the perspective of welfare economics, power-generating enterprises have demonstrated positive externalities, which make social cost deviate from private and thus gives rise to defects in allocation of resources. The existence of externalities proves that market is not omnipotent: it cannot automatically lead to the equilibrium between pains and gains from all parties in the market, and adjustment and improvement are needed to reduce deficiency. Externalities are important a subject in new institutional economics and it has been applied to environmental protection. Reference [5] discusses new mechanism for carbon market with externalities. The theory of externalities has also been adopted in the electric power industry; Reference [6] analyses the rationality and feasibility of new energy policies in Europe, while [7] studies the economic evaluation of power plants with externalities.

\section{THE THEORY OF EXTERNALITIES}

\subsection{Definition}

The concept of externalities, also called external effects or external influences, was put forward by Marshall and Pigou from Cambridge University, and it has attracted lots of attention from economists who have made in-depth study from various perspectives. Different economists have defined externalities in their own ways. Simply, when one's behavior exerts influences on the effect or welfare of others, and these influences cannot be eliminated by the market spontaneously (through rewards or compensation), they are called externalities.

\subsection{Influence of Externalities on the Allocation of Social Resources}

Externalities make marginal social cost deviate from marginal private cost (cost paid by producer for producing the last unit of goods), and resources do not have optimal allocation. The deviation between social cost and private cost can be expressed as

$$
M S_{C}=M P_{C}+M E_{C}
$$

In the equation, $M S_{\mathrm{C}}$ stands for marginal social cost, $M P_{\mathrm{C}}$ for marginal private cost, and $M E_{\mathrm{C}}$ stands for the total cost of externalities.

Influences of externalities on the allocation of social resources are illustrated in Figure 1. The horizontal axis represents the quantity of product $Q$, 
and vertical axis represents the price of product $P r$, and line $\mathrm{n}$ stands for the demand of product.

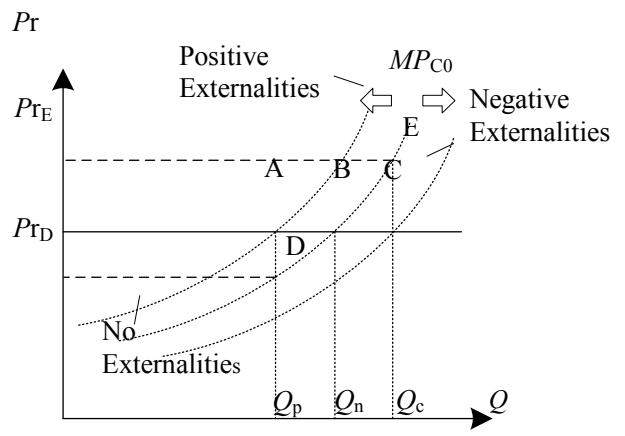

Figure.1 Influence of externalities on social resources

If there are no externalities, which means in Equation (1) $M E_{\mathrm{C}}=0$, marginal social cost $M S_{\mathrm{C} 0}$ equals to marginal private cost $M P_{\mathrm{C} 0}$ as shown by point $\mathrm{B}$. Under this circumstance, producers gain the maximum profit while social demand $Q_{\mathrm{n}}$ is met, and the curve of marginal private cost can also represent marginal opportunity cost.

If positive externalities exist, the behavior of the producer reduces the cost of others; in this case, $M E_{\mathrm{C}}<0$, and the curve marginal private cost shifts from the curve of marginal social cost to the left side. The equilibrium point at which maximum profit can be obtained moves from point B to point A. Although producers can still get maximum profit at point A, the quantity of production has dropped to $Q_{\mathrm{p}}$, which cannot satisfy social demand $\left(Q_{\mathrm{n}}\right)$. In addition, the price of product is now higher than that defined by the curve of marginal social cost (point D), which means $P r_{A}>P r_{D}$.

If negative externalities exist, the behavior of the producer increases the cost of others; in this case, $M E_{\mathrm{C}}>0$, and the curve of marginal private cost shifts from the curve of marginal social cost to the right side. The equilibrium point at which the maximum profit can be obtained moves from point B to point $\mathrm{C}$, and the quantity will be expanded to $Q_{\mathrm{C}}$, exceeding social demand $Q_{\mathrm{N}}$. In addition, the price of product will be lower than that defined by the curve of marginal social cost, which means $\operatorname{Pr}_{\mathrm{E}}>\operatorname{Pr}_{\mathrm{C}}$.

In summary, positive externalities reduce the quantity of product and increase its price, while negative externalities increase the quantity and reduce the price. Thus, externalities exert negative influences on the allocation of social resources.

\section{LAYOUT OF TEXT}

In the light of welfare economics, EPAS obviously demonstrates the features of externalities. Service such as automatic generation control (AGC), peak shaving, reactive power regulation, hot backup and black start is a basic guarantee for an electric power system, and they benefit all the users. Auxiliary service of power-generating enterprises influences the welfare cost of users. Therefore, the cost of such service should be compensated through proper approaches to eliminate the externalities and optimize the allocation of social resources.

\subsection{Definition and Category of Externalities of EPAS}

The definition of externalities of EPAS can be described as the deficit or surplus of spill-over auxiliary service from enterprises when their powergenerating units operate in a flat-rate system where auxiliary service is not charged.

The occurrence of externalities of EPAS can be analyzed from two major market parties: the producer and the consumer, which are the subject and object of the externalities respectively. In this case, the relationship between the subject and the object can be further divided into the following four categories, which include all the external effects of EPAS.

- Some producers are the subject and other producers are the object. For example, a certain type generating units may be limited by its features to provide auxiliary service in the system, so related services need to be provided by other units, whose efficiency and effectiveness will be affected (negative externalities). Or, in contrast, a certain type of units perform so well that it can take a large share of auxiliary service from other units, letting other units operate with stable loads and improving the efficiency of the whole group (positive externalities).

- Producers are the subject and consumers are the object. For instance, malfunctioning generators will lead to deficit of electricity amount and causing loss to consumers (negative externalities), but and hydroelectric station will become a place of interests for tourists (positive externalities).

- Consumers are the subject and producers are the object. A typical case is that a consumer frequently changes his load and increase the demand for auxiliary service, in which the producer needs to provide more services but consumer does not need to pay more (negative externalities).

- Some consumers are the subject and other consumers are the object. Behavior like frequently changing the load will affect the quality of electricity of other uses, reducing the production efficiency (negative externalities); or some users provide reactive power service or voltage support, which improve the quality and benefit other users (positive externalities).

\subsection{Influence of Externalities of EPAS}

Externalities of EPAS will without doubt exert technological and economical influences on power grid enterprises. Deficiencies of auxiliary service 
caused by externalities will increase cost for electric power transaction and change the distribution of power flow.

\subsubsection{Influence on Power Grid}

EPAS, such as peak-shaving and frequency modulation, is a basic guarantee for the safe and stable operation of power system. The existence of externalities has deprived power-generating enterprises with positive external effects from getting compensation, and exempted those with negative effects from bearing the loss. In the long run, EPAS cannot achieve optimal resources allocation, which will lead to market failure and the malfunction of power grids.

\subsubsection{Influence on Power Flow Distribution of Electric Power System}

If all the EPAS within a system is concentrated on some certain power-generating units, the distribution of power flow will be affected. For instance, if the AGC service of a system is performed by one particular unit, the change of power flow in that unit might be drastic. Another example is wind turbine generator. Since wind power projects are deeply influenced by state policies and the investing capacity of enterprises, there exist uncertainties in their development and construction. Due to the randomness of wind power, the distribution of power flow will also face a lot of indeterminacy after wind power is widely put into use.

\subsubsection{Influence on the Cost of Power Purchase Cos- tof Electric Power Enterprises}

As explained above, externalities of EPAS will lower the efficiency of market and increase the cost of electric power transaction, which will also raise the cost of power purchase for power grid enterprises. For wind turbine generators, related departments have issued some administrative measures for the price of power-generation and the cost allocation of renewable resources, which stipulates that the price difference between the cost of electricity generated from renewable resources and that from generators fired by desulfurized coal will be apportioned based on the electric power sales of the grids of and beyond provincial level. But even with such advantages, it is not profitable for powergenerating enterprises to purchase a large quantity of renewable energy, because electricity provided from generators fired by desulfurized coal through electricity price bidding has been expensive. Therefore, purchasing a large amount of electricity with high price will definitely raise the average price of purchase.

\subsubsection{Influence on Power-generating Enterprises}

For the owner of power-generating units with positive externalities which is an independent economic entity, the enterprise has paid cost for extra auxiliary service, but does not have proper compensation. This to some extent deprives the incentive of enterprises to provide auxiliary service and to upgrade equipments and technology. If such externalities cannot be eradicated, the efficiency of enterprises cannot be guaranteed, which will further jeopardize the operation of enterprises and development of power grids.

A typical example about negative externalities from EPAS is wind turbines. According to the national requirements, all the electricity generated by wind turbine generators must be put into service through the power grids. Therefore, on one hand, power-generating enterprises need to analyze the current situation of power grids and study problems such as opening mode of generating units, network constraints for power output and stability limits for grids. Specialized construction and improvement are needed to deal with the bottleneck of grids and enhance their capacity to match with wind power so that their negative externalities can be eliminated. On the other hand, our government should formulate regulations for economic compensation with the consultation of enterprises; through economic adjustments and regulations, conflicts between power plants and power grids and conflicts of dispatch and distribution due to the lack of mechanism to justify interests can be solved and reduced. In this way, a smooth transition of management and an orderly linkup can be guaranteed, and grids can operate safely and stably.

\section{SUGGESTIONS FOR ERADICATING EXTERNALITIES OF EPAS}

\subsection{Pigovian Solutions: Government Intervention}

At the primary stage of "separating power plants from power grids" in china, the price for power transmission and distribution was tightly controlled, because the change of production price and sales price of electricity was not interrelated, and power grid enterprises could not afford EPAS. Therefore, a mechanism in which government intervenes power price of auxiliary service for consumer should be established to improve the assessment and compensation.

The majority of the EPAS are provided by units of power plants. The cost for plants to support such services includes equipment costs, opportunity cost for getting fewer revenues in the active services market, increasing costs for every unit of power generated and so on. In traditional monopoly power enterprises, they alone would take charge of the whole process from production to consumption; 
whether to provide power or auxiliary service would be totally determined by dispatching, so there were no such problems as individual accounting or charging for auxiliary service. However, in a marketbased power industry, if power plants are paid merely for how much electricity they provide, their goals would be to deliver as much output as possible, paying no attention to auxiliary service.

According to the assessment and compensation measures available, after the total amount of assessing fees for grid-connection management and the total amount of compensation for paid services are decided, the price spread will be shared by power-generating enterprises at provincial level based on their revenues or total power volume. As a matter of fact, power-generating enterprises have to afford all the cost of auxiliary service, which does not align with general principles of economics. Consequently, proper share of services cost can be directed to consumers following the principle of "paid by beneficiaries".

\subsection{Coase Solution: Market Transaction}

Coase has reiterated the significance of market, which in some cases is more potent than government intervention. The application of Coase's theory, such as the mechanism of trading pollution right, has proven his views.

To build up the market of EPAS is a fundamental solution to externalities. With the development of electric power production and the mechanism of assessment and compensation, various parties in the market have acquired deeper understanding about the market of auxiliary service; therefore, it is feasible to establish and improve the market of auxiliary service on the present technological system.

Actually, auxiliary service market and energy market are essentially similar. Firstly, they have similar requirements for market parties and their basic rules and concepts are homogeneous. Secondly, they can share the technological supporting systems which are open-typed and in pursuit of safety, completeness, consistency and expansibility. Thirdly, it takes time to build up an electric power market as proven by mature overseas markets, which are based on the full development of installing capability. Consequently, our country should adopt a way that is suitable to our situation. The cost of auxiliary service generally accounts for $2 \%$ to $10 \%$ of basic energy cost or even lower. Thus, it is proper to establish auxiliary service market at first and leave issues like operation status and market share decided by competition. In other words, externalities of EPAS should be eradicated through market mechanism.

\section{CONCLUSION}

EPAS serves as a guarantee for the stable and safe operation of electric power systems. Though it is beset with externalities, EPAS benefits all the users and affects their welfare cost. Therefore, these externalities should be eliminated by proper compensation to optimize resources allocation. To achieve this goal, this thesis makes in-depth study into the externalities of EPAS and the Pigovian solution for government intervention, the mechanism of assessment and compensation. At last, the market based Coase solution is put forward, suggesting the establishment of EPAS market, which is also the goal of electric power reform of china.

\section{REFERENCES}

[1] Ge Ju, ZhangLi-zi, Zhou Xiao-bing, et al. "Discussion on AGC UnitsParticipating Ancillary Services in Electricity Market". Power System Technology, 2002, 26(12): 61-65.

[2] Ding Ming, An Ling, Qi Xian-jun. "Reserve Dispatch Considering System Reliability in Electricity Market environment". Relay, 2007, 35(15):14-17.

[3] Zhang Shao-hua, Fang Yong, Li Yu-zeng. Incentive mechanism design in electricity markets. Power System Technology, 2003, 27(1): 52-56.

[4] Yao Zhu-xiang, Zhou Gen-hua, Luo Qi. “Auxiliary service deterministic performance index of AGC units and its usage". Central China Electric Power, 2007, 20(5): 10-22, 24.

[5] Eric Gimon, Sonia Aggarwal and Hal Harvey. "A New Approach to Capabilities Markets: Seeding Solutions for the Future". The Electricity Journal, 2013, 26(6): 20-27.

[6] Paul Lehmann, Felix Creutzig, Melf-Hinrich Ehlers, et al. "Carbon Lock-Out: Advancing Renewable Energy Policy in Europe". Energies, 2012, 5: 323-354.

[7] M.N. El-Kordya, M.A. Badr, K.A. Abeda, et al. Economical evaluation of electricity generation considering exter-nalities. Renewable Energy, 2002, 25: 317-328.

[8] J. K. Wu, "Two Problems of Computer Mechanics Program System," Proceedings of Finite Element Analysis and CAD, Peking University Press, Beijing, 1994, pp. 915 .

[9] L. Honeycutt, “Communication and Design Course," 1998. http://dcr.rpi.edu/commdesign/ class1.html

[10]O. Wright and W. Wright, "Flying-Machine," US Patent No. 821393, 1906. 